\title{
Abdoulaye Imorou (dir.), La littérature africaine francophone. Mesures d'une présence au monde
}

\section{Emanuela Cacchioli}

\section{(2) OpenEdition}

1 Journals

\section{Edizione digitale}

URL: http://journals.openedition.org/studifrancesi/4496

DOI: 10.4000/studifrancesi.4496

ISSN: 2421-5856

\section{Editore}

Rosenberg \& Sellier

\section{Edizione cartacea}

Data di pubblicazione: 1 settembre 2016

Paginazione: 373-374

ISSN: 0039-2944

\section{Notizia bibliografica digitale}

Emanuela Cacchioli, « Abdoulaye Imorou (dir.), La littérature africaine francophone. Mesures d'une présence au monde », Studi Francesi [Online], 179 (LX | II) | 2016, online dal 01 septembre 2016, consultato il 18 septembre 2020. URL : http://journals.openedition.org/studifrancesi/4496 ; DOI : https://doi.org/10.4000/studifrancesi.4496

Questo documento è stato generato automaticamente il 18 settembre 2020.

\section{(c) $(1) \ominus$}

Studi Francesi è distribuita con Licenza Creative Commons Attribuzione - Non commerciale - Non opere derivate 4.0 Internazionale. 


\title{
Abdoulaye Imorou (dir.), La littérature africaine francophone. Mesures d'une présence au monde
}

\author{
Emanuela Cacchioli
}

\section{NOTIZIA}

La littérature africaine francophone. Mesures d'une présence au monde, sous la direction de Abdoulaye IMOROU, Dijon, Éditions Universitaires de Dijon, 2014, 277 pp.

1 Il volume si presenta come una collettanea di articoli che intende indagare lo status delle letterature francofone, in quanto insieme di testi di espressione francese. Sebbene il dibattito intorno alla definizione della letteratura francofona non conosca sosta, la critica e le istituzioni culturali le hanno progressivamente accettate e inglobate. Anzi, secondo i firmatari del manifesto Pour une littérature monde, saranno proprio le letterature francofone a rinnovare i discorsi e le forme della letteratura di espressione francese, dal momento che i testi prodotti in Francia sembrano troppo condizionati dalla tradizione e gli autori paiono aver perso spinta creativa. Molti autori francofoni dell'ultima generazione ricercano proprio questa rottura e adottano un'ottica transnazionale per assicurare ai loro testi e alle letterature francofone un posto di rilievo nel panorama della letteratura generale. Il volume si sofferma, in particolare, sull'ambito africano, ma occorre precisare che questa etichetta indica realtà differenti. Proprio per rendere conto della polifonia e della peculiarità che ogni letteratura africana apporta al dibattito e alla produzione di testi, nel volume vengono raccolti contributi che tengono conto di questa dimensione plurale.

2 L'opera è suddivisa in due parti. La prima sezione, dal titolo «Présence dans le monde littéraire» (pp. 18-151) analizza sotto diverse sfaccettature il rapporto che intercorre tra l'Africa e la scena mondiale. Jean Chrysostome NKEJABAHIZI, Le monde littéraire et le retard coupable d'une Afrique francophone mal en point (pp. 19-29) focalizza il suo 
contributo sulla relativa autonomia delle letterature africane e sulle potenzialità di sviluppo sia del mercato editoriale che del discorso critico. François PRovenzano (Ce que Sartre fait à la négritude. Archéologie d'un discours francodoxe, pp. 31-44), si sofferma sul peso della «francodoxie» e dell'interpretazione di Sartre nella lettura delle opere africane. Isaac BAZIÉ, (Violences postcoloniales et "Weltliteratur": de l'écart éthique à la norme esthétique. Francophonie littéraire et comparatisme, pp. 45-59) pone al centro delle sue riflessioni l'orizzonte di attesa dei lettori africani e le conseguenti scelte degli scrittori costretti così a limitare la loro vena creativa. Lynda-Nawel TEBBANI-ALAOUACHE ( La nouvelle littérature algérienne ou le procédé poétique de l'altérité, passer de l'écriture de l'autre à l'écrire autrement, pp. 61-73) affronta il caso di Mourad Djebel e El Mahdi Acherchour, due autori ignorati dalla critica per aver preso le distanze dalle tematiche tradizionali della letteratura algerina, proposte ad esempio in Nedjma di Yacine. Lo stesso romanzo è il fulcro attorno al quale ruota il contributo di Kaoutar HARCHI (Jeu de la critique et critique du Je. Lectures et orientations idéologiques de "Nedjma" de Kateb Yacine, pp. 75-84). Nella seconda parte della prima sezione trova spazio l'articolo di Anthony MANGEON (Pour une histoire littéraire intégrée (des centres aux marges, du national au transnational: littératures françaises, littératures francophones, littératures féminines), pp. 87-104) che invoca la creazione di un canone letterario di testi da insegnare a scuola e all'università. Abdoulaye IMOROU (Le texte littéraire africain et ses lectures. À propos du paradigme de la spécificité africaine, pp. 105-120), affronta la questione della ricezione del testo africano e si augura che esso venga maggiormente letto come un prodotto transcontinentale. L'uso dei media all'interno delle opere africane è il tema trattato da David K. N'GORAN in De la mise en scène (médiatique) dans le champ littéraire africain. Genèse et structure d'un capital symbolique (pp. 121-134). Da ultimo, Lotte ARNDT (Chantiers d'un féminisme postcolonial dans la revue "Africultures"? Conjonctures des stratégies discursives, pp. 135-151), offre un'analisi dei dossier che la rivista dedica alle donne africane.

3 La seconda sezione, dal titolo «La littérature africaine et le souci du monde» (pp. 155-249), si apre con Les enfants de la postcolonie et de la République mondiale des Lettres (pp. 155-168) in cui Babou DIÈNE studia le novità estetiche e tematiche nei testi degli autori postcoloniali. Anche i contributi di Pierre NDEMBY MAMFOUMBY (Actorialisation et spatialisation comme motifs de l'écart et de la norme dans "Le paradis des choits" et "Al Capone le Malien" de Sami Tchak, pp. 169-176) e di A. Mia Élise ADJOUMANI (Quand la littérature africaine francophone devient individualiste. Une lecture de "Verre cassé" d'Alain Mabanckou et "Babyface" de Koffi Kwahulé, pp. 177-186) proseguono lo stesso filone di indagine e mettono in luce altri aspetti di innovazione introdotti da autori contemporanei, quali ad esempio la scelta di ambientare i romanzi non in Africa, l'elogio dell'individualismo e la retorica del senso della collettività. Tutti aspetti che conferiscono una dimensione transnazionale alle opere di questi autori. Perpétue DAH (L'Afrique dans le jeu littéraire mondial: entre désir d'universalité et besoin de témoignage, pp. 187-198), dal canto suo, mette a confronto le opere di Alain Mabanckou e di Patrice Nganang per trovare un punto d'incontro tra due scrittori così apparentemente distanti. Annick GENDRE (Le motif de l'androgyne dans "Le livre du sang". Pour une dialectique nouvelle pour l'Afrique, pp. 199-212), analizza invece l'androginia in quanto motivo utile a sovvertire le categorie attraverso le quali viene pensata l'Africa. Nella seconda parte della seconda sezione i contributi indagano le modalità che permettono alla finzione di interessarsi alla realtà e di stabilire una relazione tra l'Africa e il resto del mondo. L'articolo di Arthur NGOIE MUKENGE, L'exil entre réalité et fiction dans "La villa belge" de Tshisungu wa Tshisungu (pp. 
215-224), si sofferma sul problema della fuga dei cervelli e invita a ripensare il rapporto Africa/Occidente. La scrittura come grido che permette di dilatare il tempo, lo spazio e di affinare la nostra capacità di analisi è il tema del contributo di David Blaise osSENE, Les paradis perdus de la parole. L'exemple du cri et de l'écrit dans les textes narratifs de Sony Labou Tansi (pp. 225-238). Chiude la collettanea Les fictions du champ du développement et le développement des fictions: une proposition d'une autre lecture de Kourouma et d'Efoui (pp. 239-249), in cui Heidi BoJSEN mette in evidenza come il lavoro delle ONG che si occupano di sviluppo in Africa venga in parte influenzato anche da alcuni testi di finzione. Il volume offre spunti di riflessione interessanti: i contributi analizzano il rapporto tra la letteratura africana, quella francofona e la letteratura in generale, allo scopo di far uscire l'Africa dallo stato di impasse in cui si trova per inserirla nella dimensione mondiale a pieno titolo, o meglio per dare rilievo critico alle varie modalità già adottate dagli autori africani che vanno proprio in questa direzione. 